\title{
Satellite-based climate information within the WMO RA VI Regional Climate Centre on Climate Monitoring
}

\author{
A. Obregón, H. Nitsche, M. Körber, A. Kreis, P. Bissolli, K. Friedrich, and S. Rösner \\ Deutscher Wetterdienst, WMO RA VI Regional Climate Centre Network Offenbach Node on Climate \\ Monitoring, Frankfurter Str. 135, 63067 Offenbach, Germany \\ Correspondence to: A. Obregón (andre.obregon@dwd.de)
}

Received: 25 January 2014 - Revised: 11 April 2014 - Accepted: 23 April 2014 - Published: 13 May 2014

\begin{abstract}
The World Meteorological Organization (WMO) established Regional Climate Centres (RCCs) around the world to create science-based climate information on a regional scale within the Global Framework for Climate Services (GFCS). The paper introduces the satellite component of the WMO Regional Climate Centre on Climate Monitoring (RCC-CM) for Europe and the Middle East. The RCC-CM product portfolio is based on essential climate variables (ECVs) as defined by the Global Climate Observing System (GCOS), spanning the atmospheric (radiation, clouds, water vapour) and terrestrial domains (snow cover, soil moisture). In the first part, the input data sets are briefly described, which are provided by the EUMETSAT (European Organisation for the Exploitation of Meteorological Satellites) Satellite Application Facilities (SAF), in particular CM SAF, and by the ESA (European Space Agency) Climate Change Initiative (CCI). In the second part, the derived RCC-CM products are presented, which are divided into two groups: (i) operational monitoring products (e.g. monthly means and anomalies) based on near-real-time environmental data records (EDRs) and (ii) climate information records (e.g. climatologies, time series, trend maps) based on long-term thematic climate data records (TCDRs) with adequate stability, accuracy and homogeneity. The products are provided as maps, statistical plots and gridded data, which are made available through the RCC-CM website (www.dwd.de/rcc-cm).
\end{abstract}

\section{Introduction}

Since the launch of the first satellites observing Earth's atmosphere in the 1970s (e.g. Meteosat-1 in 1977), more than 30 years of satellite imagery have become available. Satellite data with adequate quality for the generation of longterm climate data sets exist since the beginning of the 1980s. Although meteorological satellites have been primarily designed for weather forecasting, substantial international efforts have been made in recent years highlighting the importance of climate monitoring and the detection of subtle trends and change in climate. In 2008, the WMO (World Meteorological Organization) network for Sustained and Coordinated Processing of Environmental Satellite Data for Climate Monitoring (SCOPE-CM) was established for the coordination of the sustainable generation of long-term climate data records (CDR), building upon essential climate variables (ECV) as defined by the Global Climate Observing System (GCOS). SCOPE-CM interfaces with the WMO Integrated Global Observing System (WIGOS) and the Global Space-based Inter Calibration System (GSICS), building an end-to-end system for climate monitoring (Lattanzio et al., 2013). CDRs are time series of measurements of sufficient length, consistency, and continuity to determine climate variability and change (NRC, 2004). They comprise homogeneous long-term data records of radiances or brightness temperatures (fundamental climate data records, FCDR) and their derived geophysical variables (thematic climate data records, TCDR). The latency of CDR product releases or updates is usually several years. A better timeliness of climate data is enabled by the provision of so-called environmental data records (EDR), which are constructed as instantaneous estimates of geophysical variables (Schulz et al., 2009). The term "interim climate data records" (ICDR) may be used if certain automated 
corrections are established in the processing system. EDRs and ICDRs are generally provided in operational mode in near-real time (NRT) and do not meet the strict requirements made for CDRs. They generally lack stability, accuracy and sufficient length for climate studies.

Since climate change and its potential impacts have boosted social demands for tailored climate services, the WMO is making substantial efforts to implement Regional Climate Centres (RCC) around the world in order to assist national meteorological and hydrological services (NMHS) to deliver better climate services and products within the Global Framework for Climate Services (GFCS). There is increasing demand for climate monitoring information to enable countries to cope with short-term climate variability (Peterson and Baddour, 2011). The WMO Regional Climate Centre Network (RA - Regional Association - VI) Offenbach Node on Climate Monitoring (www.dwd.de/rcc-cm) provides reliable services based on scientific standards and made available in an operational mode. Figure 1 illustrates where RCC-CM interfaces in the concept of a sustained climate information flow. Formally, the primary users of RCCs are the NMHS, which provide their national end users with the needed information. However, most RCC-CM products are freely available via the web portal (refer to Sect. 4). The acquisition of users is an ongoing effort, e.g. through participation in international projects (e.g. EU FP7 project EUPORIAS, www.euporias.eu). The RCC-CM product portfolio is based on an implementation plan agreed at the 15th session of the WMO RA VI and comprises in situ-based and satellite-based products. The satellite component of RCC$\mathrm{CM}$ offers various products spanning the atmospheric (radiation, clouds, water vapour) and terrestrial domain (snow cover, soil moisture).

Major challenges remain in the understanding of interaction processes between water vapour and clouds as well as their radiative impact (Schulz et al., 2009). Cloud properties, surface radiation budget and water vapour are defined by GCOS as ECVs. Clouds play a crucial role in the climate system by altering Earth's radiation and water balance. Clouds have a large influence on climate but, in turn, a changing climate will also affect the formation of clouds. Monitoring of the shortwave and longwave fluxes at Earth's surface is of crucial importance for the understanding of the climate system and for the detection of global and regional changes. Water vapour in the atmosphere is the most important greenhouse gas and the main contributor to the natural greenhouse effect. Since warmer air can hold more moisture, the water vapour in the atmosphere is directly related to temperature. Monitoring the spatial distribution of water vapour is therefore of great interest.

Sunshine duration (SD), together with surface temperature and precipitation, is one of the most important and widely used parameters in climate monitoring and a key variable for various sectors, including tourism, public health, agriculture, vegetation modelling, and solar energy applications. SD is

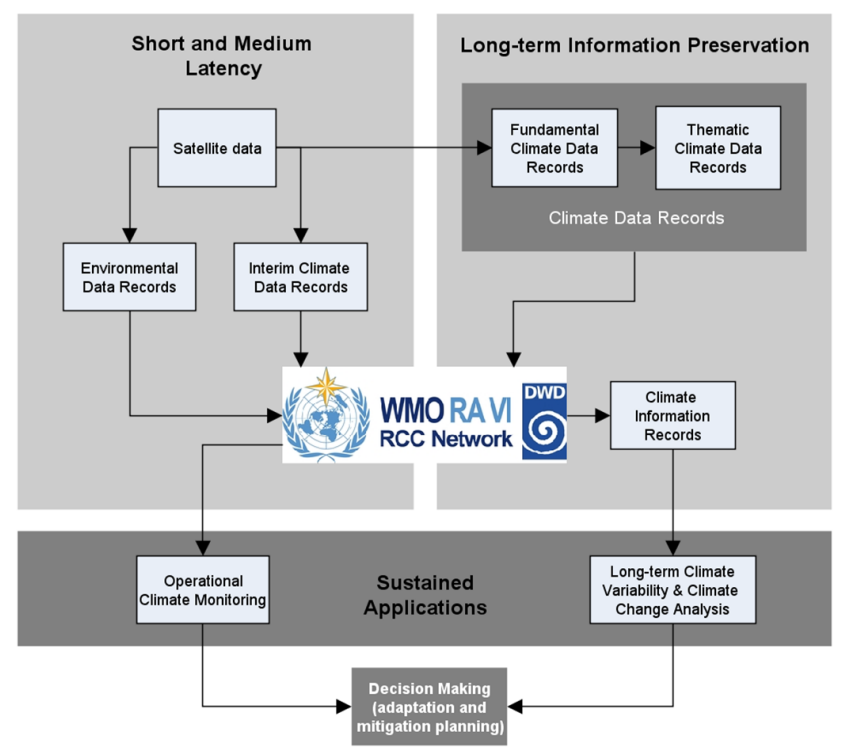

Figure 1. Sustained climate information flow and the interfaces with RCC-CM. Figure adapted and modified from Dowell et al. (2013, Fig. 6.2) and WMO (2012, Fig. 2).

strongly related to the ECVs cloud properties and surface radiation budget (Kothe et al., 2013).

Soil moisture is a key parameter in the water, energy and carbon cycles and a critical variable in monitoring hazards such as floods and droughts. It is of high relevance for a variety of agricultural and environmental applications. Therefore, soil moisture was recognized as an ECV by GCOS and as a second top-priority parameter by the Group on Earth Observation (GEO). Within the RA VI RCC Network (www.rccra6.org) it was recommended to consider adding soil moisture products to the product portfolio.

Snow properties are highly sensitive to changes in temperature and precipitation and are therefore a strong indicator for climate variability and change. A global decline of snow would affect planetary albedo, soil moisture, vegetation growth and the hydrological balance (GCOS, 2011). The monitoring of snow properties is therefore of great importance.

\section{Variables and data sets}

The atmospheric data used are provided by the EUMETSAT (European Organisation for the Exploitation of Meteorological Satellites) Satellite Application Facility on Climate Monitoring (CM SAF) (Schulz et al., 2009), while the terrestrial data are mainly provided by other EUMETSAT SAFs and the ESA (European Space Agency) Climate Change Initiative (CCI) (Hollmann et al., 2013). Table 1 gives an overview on all data sets used for the generation of the RCC-CM climate monitoring products. Input data are near-real-time data (for the generation of operational climate monitoring products) 
Table 1. RCC-CM satellite-based climate variables and corresponding input data sets (EDR - environmental data record, ICDR - interim climate data record, TCDR - thematic climate data record).

\begin{tabular}{lll}
\hline Variable & EDR/ICDR & TCDR \\
\hline Global radiation & CM SAF SIS SEVIRI & CM SAF SIS MVIRI 1983-2005 \\
Direct radiation & CM SAF SID SEVIRI & CM SAF SID MVIRI 1983-2005 \\
Cloud fractional cover & CM SAF CFC AVHRR-LAC & CM SAF CFC CLARA-A1 1982-2009 \\
Cloudy/sunny days & CM SAF CFC AVHRR-LAC & CM SAF CFC CLARA-A1 1982-2009 \\
Total water vapour & CM SAF TPW ATOVS & CM SAF TPW ATOVS 1999-2001 \\
Surface albedo & CM SAF SAL AVHRR-LAC & CM SAF SAL CLARA-A1 1982-2009 \\
Sunshine duration & CM SAF SID SEVIRI & CM SAF SID MVIRI 1983-2005 \\
Soil moisture & H-SAF SM-DAS-2/Geoland2 SWI & ESA Soil Moisture CCI 1978-2010 \\
Snow cover extent & H-SAF AVHRR SN-OBS-3 & ESA GlobSnow 1995-2012 \\
\hline
\end{tabular}

and climate data records (for the generation of climate information records); see also Fig. 1.

\subsection{Clouds, radiation and water vapour}

RCC-CM uses input data provided by CM SAF for the following parameters:

- cloud fractional cover (CFC)

- global radiation (surface incoming shortwave radiation, SIS)

- direct radiation (surface incoming direct radiation, SID)

- surface albedo (SAL)

- total precipitable water (TPW).

CM SAF data are based on instruments on geostationary (GEO) and polar-orbiting (LEO) satellites. The CFC product is based on the AVHRR (Advanced Very High Resolution Radiometer) instrument, flying on the NOAA (National Oceanic and Atmospheric Administration) and MetOp satellites. CFC refers to the fraction of clouds within each grid box. Fractional cloud cover is expressed as percent. The accuracy of the near-real-time CFC product for Europe is defined as $\pm 10 \%$ compared to MODIS (Moderate Resolution Imaging Spectroradiometer). A CDR of climate quality is provided with the AVHRR-based CLARA (cloud, albedo and radiation)-A1 data set (Karlsson et al., 2013) which has a high accuracy and stability for analysis of climate variability and change. This data set also includes SAL.

SIS and SID refer to global and direct radiation (global minus diffuse radiation), respectively. RCC-CM SIS and SID products are based on CM SAF data sets using data from geostationary Meteosat satellites. The near-real-time products are based on the SEVIRI (Spinning Enhanced Visible and Infrared Imager) and GERB (Geostationary Earth Radiation Budget) instruments. The accuracy of the CM SAF input data is defined as $90 \%$ of absolute bias values below $10 \mathrm{~W} \mathrm{~m}^{-2}$ compared with in situ data (plus the uncertainty of ground based measurements) for monthly means. Higher bias values occur in the Alpine and other mountainous regions, e.g. due to uncertainties in area to point comparison. An MVIRI (Meteosat Visible and Infrared Imager)-based climate data record (1983-2005) is provided for SIS and SID (Posselt et al., 2012).

CM SAF provides several water vapour products, including the TPW, which represents the vertically integrated water vapour of an atmospheric unit's vertical column. The accuracy of the near-real-time TPW product is defined as a bias of $1 \mathrm{~mm}$ and a RMSE (root mean square error) of $4.5 \mathrm{~mm}$ using GUAN (GCOS Upper Air Network) radiosondes as a reference. A CDR for TPW exists, but only for a relatively short period covering the years 1999-2011 (ATOVS edition 1). Due to missing intercalibration for the first years, only data between 2001 and 2011 are used within RCC-CM.

\subsection{Sunshine duration}

The RCC-CM sunshine duration products are derived by using a simple method proposed by Kothe et al. (2013) using hourly CM SAF SID data. The method is based on the WMO definition for bright sunshine, occurring when direct solar radiation exceeds a threshold of $120 \mathrm{~W} \mathrm{~m}^{-2}$ (WMO, 2008). An evaluation by product intercomparison and validation against station measurements showed a good agreement with accuracy within the range of $\pm 1 \mathrm{hday}^{-1}$. The uncertainty of the satellite products is quite homogeneous over land in comparison to products based on station interpolation, whose uncertainty increase in areas with low station density or in mountainous regions. The satellite-derived SD product gives valuable additional spatial information over the European continent (Kothe et al., 2013). The SEVIRI-based SID near-realtime products are used for the generation of operational SDmonitoring products, while the MVIRI-based SID climate data record is used for the generation of a long-term data set, which can serve as reference climatology and for climaterelated studies. 


\subsection{Soil moisture}

A 32 year long surface soil moisture data set (1978-2010) was derived within the ESA Soil Moisture CCI by combining active and passive satellite instruments, with emphasis on preserving long-term trends (Liu et al., 2012; Wagner et al., 2012). RCC-CM long-term climate information records are based on this data set. RCC-CM near-real-time soil moisture monitoring products are currently in development and will be based on the soil moisture profile (also: root-zone soil moisture), which also characterizes the soil wetness in deeper soil layers. One candidate for the operational monitoring product is the ASCAT (Advanced Scatterometer)-based product provided by the Satellite Application Facility on Hydrology (H-SAF; SM-DAS-2 product), which uses a soil moisture assimilation system, propagating the surface observation from ASCAT towards the roots region. A second candidate is the soil water index (SWI), provided within the Copernicus Geoland2 project. SWI is derived by an exponential filter simulating the soil moisture value of deeper soil layers (Brocca et al., 2010).

\subsection{Snow cover}

Recently, a long-term data set of snow extent (SE) for the years 1995-2012 has been developed within the ESA GlobSnow project, which relies on a method by Metsämäki et al. (2012). The ESA GlobProjects form a series of precursor projects for ESA CCI. SE is given as fractional snow cover in percentage per satellite grid cell. The GlobSnow SE data set is based on optical data from Envisat's AATSR (Advanced Along Track Scanning Radiometer) and ERS-2's (European Remote-Sensing satellite) ATSR-2 sensors covering the Northern Hemisphere. According to GlobSnow this is the longest historical time series of SE with a moderate spatial resolution and potentially the highest thematic accuracy available. RCC-CM uses the monthly SE composites. In addition to the long-term series, GlobSnow initiated an operational near-real time service in October 2010 based on AVHRR and NPP (National Polar-orbiting Partnership) Suomi VIIRS (Visible Infrared Imaging Radiometer Suite) instruments. The GlobSnow NRT product was selected as a candidate for an operational monitoring within RCC-CM. A second candidate is the H-SAF effective snow cover product (SN-OBS-3) which is currently in a pre-operational stage. Monitoring of snow water equivalent will be considered in the future.

\section{Products}

The RCC-CM products fall into two main categories:

1. Operational climate-monitoring products based on nearreal-time data (with adequate timeliness).
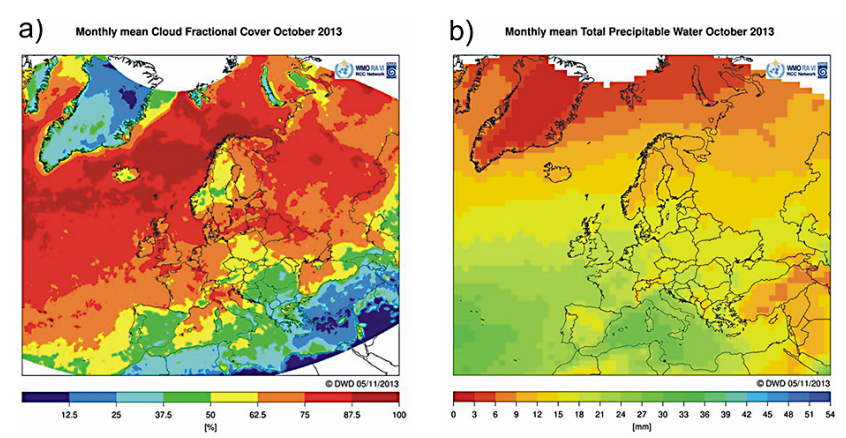

Figure 2. Monthly means of cloud fractional cover (a) and total precipitable water (b) for October 2013.

2. Climate information records based on long-term climate data records (with adequate accuracy, homogeneity and stability).

RCC-CM products are provided as maps, statistical plots and gridded data. Monthly, seasonal and annual products are generated, which are available for Europe $\left(60^{\circ} \mathrm{W}-60^{\circ} \mathrm{E}, 30^{\circ}-\right.$ $80^{\circ} \mathrm{N}$ ) and the following sub-regions:

$$
\begin{aligned}
& \text { - northern Europe }\left(25^{\circ} \mathrm{W}-40^{\circ} \mathrm{E}, 55^{\circ}-70^{\circ} \mathrm{N}\right) \\
& \text { - central Europe }\left(15^{\circ} \mathrm{W}-25^{\circ} \mathrm{E}, 45^{\circ}-60^{\circ} \mathrm{N}\right) \\
& \text { - Mediterranean }\left(10^{\circ} \mathrm{W}-40^{\circ} \mathrm{E}, 30^{\circ}-45^{\circ} \mathrm{N}\right) \\
& \text { - eastern Europe }\left(15^{\circ}-45^{\circ} \mathrm{E}, 40^{\circ}-60^{\circ} \mathrm{N}\right) .
\end{aligned}
$$

The geographic coordinates of the given regions refer to the statistical products "annual course" (Sect. 3.1.4), "time series" (Sect. 3.2.3) and "spatio-temporal diagrams" (Sect. 3.2.4). The maps show a slightly larger coverage. All analyses were carried out using climate data operators (CDO) and the statistical software R.

\subsection{Operational climate monitoring}

\subsubsection{Means}

The input data sets presented in Table 1 are mainly provided as monthly means, except for the cloud indices for which daily data are used and for sunshine duration for which hourly data are used. For the RCC-CM mean products several pre-processing steps are made including format conversion, geographic subsetting and remapping onto a regular latitude-longitude grid. The spatial resolution of the target grid depends on the original input data set and ranges between $0.05^{\circ} \times 0.05^{\circ}$ and $1^{\circ} \times 1^{\circ}$. Figure 2 shows monthly mean products of cloud fractional cover $\left(0.25^{\circ} \times 0.25^{\circ}\right.$ resolution) and total precipitable water $\left(1^{\circ} \times 1^{\circ}\right.$ resolution $)$.

Seasonal and annual means are calculated by averaging of monthly means. If missing values occur, no seasonal or annual means are derived for the respective grid box. For the production of maps, data have been transformed to a rotated 
$0.1^{\circ} \times 0.1^{\circ}$ lat-long grid using bilinear resampling. TPW data have been resampled to a rotated $1^{\circ} \times 1^{\circ}$ lat-long grid. Maps for all other product types are produced in the same way.

\subsubsection{Anomalies}

Monthly, seasonal and annual anomalies are calculated using the corresponding means (Sect. 3.1.1) and long-term averages (Sect. 3.2.1). The reference climatology for each variable is built from the corresponding climate data records (refer to Table 1).

The following types of climate anomalies are calculated:

- absolute anomalies (absolute deviations from the longterm average)

- relative anomalies (deviations from the long-term average expressed as percentage)

- standardized anomaly (absolute deviation expressed as times of standard deviation)

- percentiles (values below or above the lower or upper tercile and decile of the probability density function of the climate element).

Absolute and relative anomalies are common standards in climate monitoring. They are easy to interpret and reveal the simple departures from the long-term average. However, they do not take into account the natural variability of a parameter at a given location. Hence, no proper statements can be made on the unusualness of an anomaly. Therefore, two different measures are introduced in RCC-CM which are able to characterize the rareness of an event by taking into account the natural variability of a parameter for every grid box. The socalled standardized anomaly uses the standard deviation as a reference while the percentile product relies on deciles and terciles derived through probability density functions. As an example, Fig. 3c shows the absolute anomaly for global radiation in July 2013. High positive anomalies occur over the Atlantic Ocean and central Europe. Figure 3d shows the standardized anomaly, revealing discrepancies between these two regions. The standardized anomalies over central Europe are lower compared to those over the Atlantic Ocean, due to a general higher natural variability of global radiation in July over central Europe (see standard deviation in Fig. 3b).

\subsubsection{Indices}

CDC daily data are used for the calculation of the indices "cloudy days" and "sunny days" according to the definition of the CCl/CLIVAR/JCOMM Expert Team on Climate Change Detection and Indices (ETCCDI). Cloudy days are defined as days where average cloud cover exceeds 6 octas, while sunny days refer to a mean cloudiness of 2 octas or below. For the monthly, seasonal and annual RCC-CM products sunny and cloudy days, respectively, are counted for the
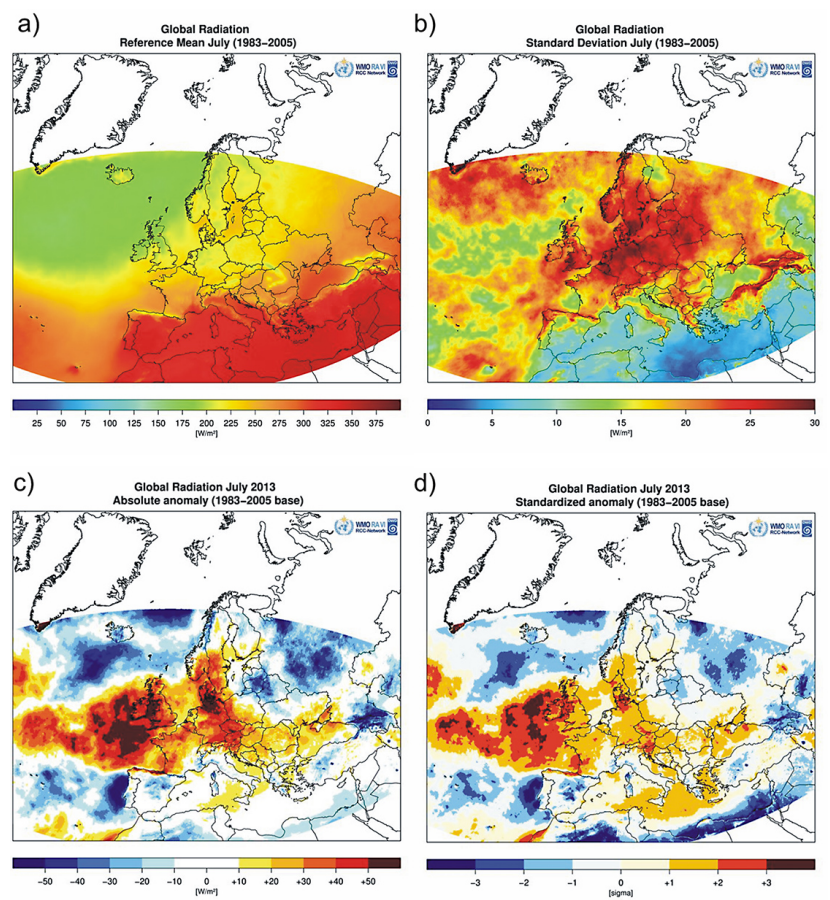

Figure 3. Analysis of global radiation for July 2013 compared to the long-term climate average of 1983-2005 (a) and the standard deviation (b). Absolute anomalies (c) and standardized anomalies (d) are shown. The upper maps fall into the category of "climate information records" while the bottom maps are "operational climate monitoring" products, which are provided on a monthly basis.

according period. Anomalies are calculated as described in Sect. 3.1.2.

\subsubsection{Annual course}

In operational climate monitoring the annual cycle of a parameter compared to its long-term average and variability is of great interest. The plots for the annual course show the mean of the current year compared to the reference climatology, based on calculations of area-weighted means. For reference, long-term means and standard deviations are shown, as well as the 10th and 90th percentiles (Fig. 4).

Figure 4 illustrates the annual course of cloud fractional cover and direct radiation for central Europe in 2013. For the beginning of the year, the products reveal well-above average cloudiness and hence negative anomalies of direct radiation in the range of the lower decile. While most of 2013 shows a normal course in terms of CFC and SID, July 2013 is a distinct exception. Cloudiness was in the range of the lower 10th percentile while direct radiation clearly exceeded the 90th percentile. This is consistent with other related parameters like sunshine duration, which was exceptionally high in central Europe in July 2013. In Germany, it was the second sunniest July on record. 

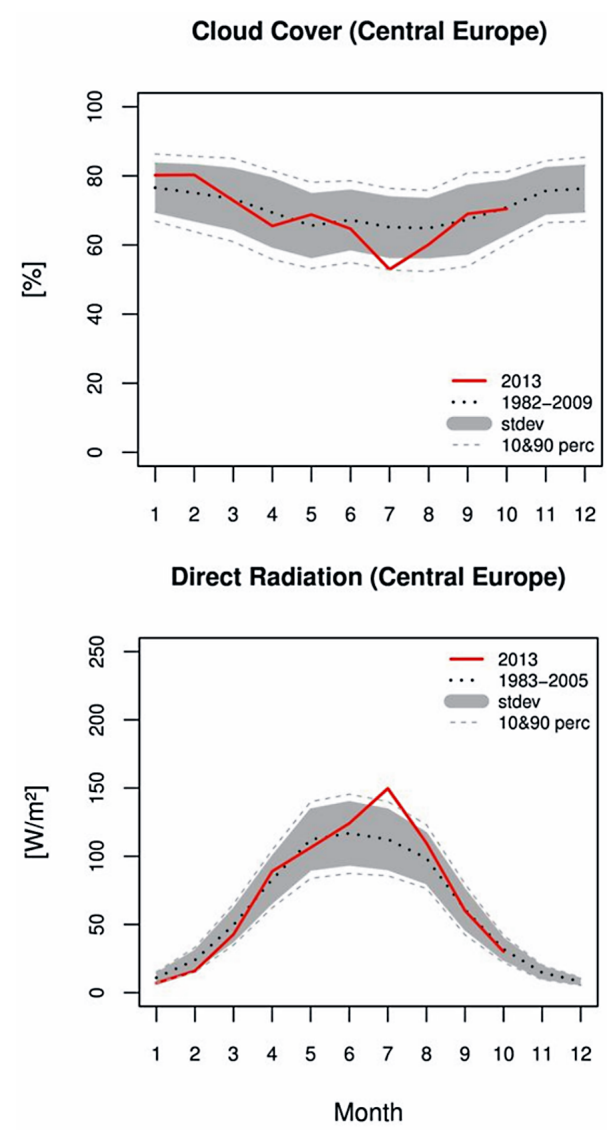

Figure 4. Annual course of monthly means of cloud cover and direct radiation for the central European subregion. Long-term averages, standard deviations and extreme percentiles are provided as a reference. The products for October 2013 are shown (provided in November 2013).

\subsection{Climate information records}

\subsubsection{Climatologies}

The climate data records in Table 1 are used for the calculation of long-term averages and standard deviations for single months, seasons and for the whole time period. The longterm averages are used as a reference for the calculation of anomalies (Sect. 3.1.2) and for the climatological interpretation of the current annual cycle (Sect. 3.1.4). In addition, long-term means and standard deviations are also provided as maps (Fig. 3a, b).

\subsubsection{Trend maps}

Monthly, seasonal and annual trends are calculated using a simple linear regression for all climate data records and provided as maps for each parameter. As an example, Fig. 5 shows the annual trend in surface soil moisture (in $\mathrm{m}^{3} \mathrm{~m}^{3} \mathrm{yr}^{-1}$ ) for the period 1979-2010, revealing a trend towards drier soils across large parts of eastern Europe.

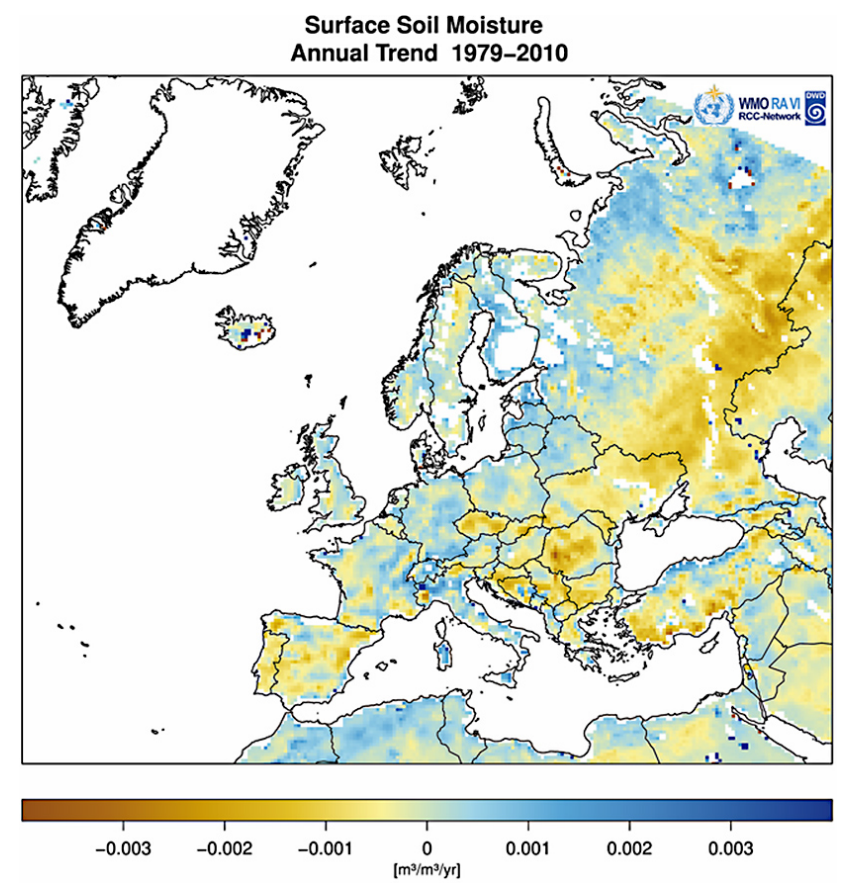

Figure 5. Annual trend in surface soil moisture for the period 19792010, based on a harmonized data set of active and passive microwave observations provided by the ESA Soil Moisture CCI.

Generally, the generation of satellite-based data sets of true climate quality which are suitable for the detection of climate trends is a major challenge. CM SAF focuses its efforts on the development of high-quality climate data records suitable for the analysis of climate variability and potentially for the detection of trends. However, since most CM SAF CDRs used within RCC-CM are version 1 data sets, there are still some issues remaining. Based on own investigations and literature review, some data sets are not used for the whole time period due to uncertain homogeneity. RCC-CM trend maps for CFC are only calculated for the period 1994-2009, since some inhomogeneities might be present before. Trend maps for SIS and SID are calculated for the period 1994-2005, since this period was found to be homogeneous in Europe. Before 1994, some shifts and artificial trends were detected (Krähenmann et al., 2013). Sanchez-Lorenzo et al. (2013) found inhomogeneities over Europe in the late 1980s and early 1990s using homogenized station data sets as the reference. Generally, the trend maps should be interpreted with caution. Also, no significance tests have been applied.

\subsubsection{Time series}

Time series are derived by calculating area-weighted means for Europe and the defined subregions using the climate data records in Table 1. The RCC-CM products show monthly, seasonal, and annual means for the whole period of the longterm record and include a 3 year running mean (Fig. 6 top). 


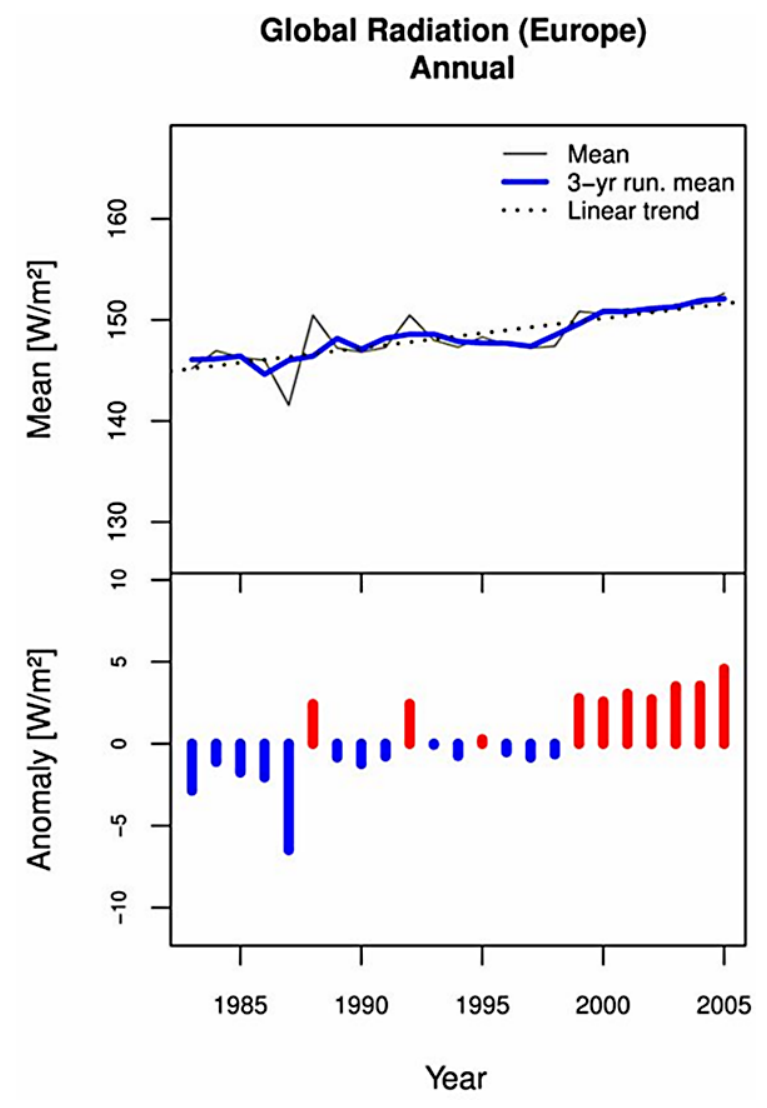

Figure 6. Time series of average annual global radiation for Europe (top) and time series of anomalies (bottom) based on the CM SAF MVIRI data set.

Time series of corresponding anomalies (absolute departures from the long-term average) are also provided (Fig. 6 bottom). The time series for mean annual global radiation is shown in Fig. 6. The data show a positive trend of global radiation in recent years, which is consistent with a decrease of cloudiness (CFC time series, not shown) and the observed global brightening (e.g. Wild, 2012). The trend in the satellite data could also be caused by inhomogeneities in the time series, though. It is known that due to possible inhomogeneities before 1994 in the CFC, SIS and SID data sets (refer to Sect. 3.2.2) time series before 1994 should be interpreted with caution.

\subsubsection{Spatio-temporal diagrams}

The visualization of climate data by means of time-latitude or time-longitude cross sections provides information about temporal and spatial variability and changes in the climate system on yearly to decadal scales. These spatio-temporal diagrams are referred to as Hovmöller plots and ease the understanding of climate dynamics (Hocke and Kämpfer, 2009).

RCC-CM provides Hovmöller diagrams for all satellite CDRs in Table 1, visualizing the temporal propagation of

\section{Cloud Cover (September)}

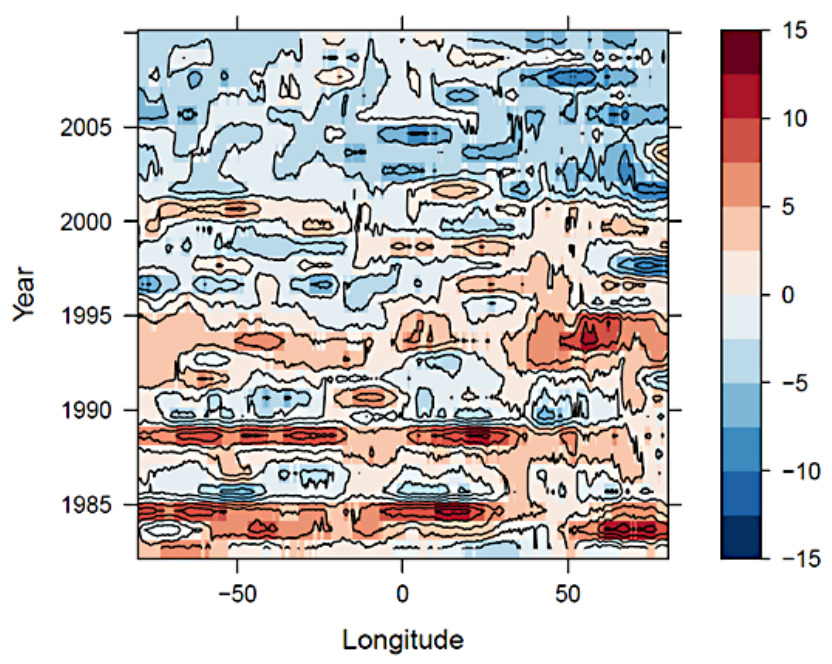

Figure 7. Hovmöller diagram of cloud cover anomalies (in \%) for Europe from 1982 till 2009 based on CM SAF CLARA-A1.

zonal and meridional anomalies. Figure 7 provides an example for the annual meridional change in cloud cover for September, revealing a tendency towards higher values in recent years, in particular over continental Europe. The cause of the trend - whether a real phenomenon or caused by instrumental inhomogeneities - should be studied thoroughly.

\section{Access, documentation and future perspectives}

The RCC-CM maps, statistical plots and gridded data are made available through the RCC-CM website (www.dwd. $\mathrm{de} / \mathrm{rcc}-\mathrm{cm}$ ). User documentation is available via so-called "product description sheets" for each climate variable. These documents provide product specifications such as spatial and temporal resolution and coverage, timeliness, data format, units and information on input data sets. The scientific methodology and data quality are briefly described and implications for usage are given. The provision of information on uncertainties and accuracies is generally of great importance. Information regarding the accuracy of the input data is provided within the product description sheets, where the corresponding provider documents are referenced. For example, the target accuracy of the CM SAF data is defined within the CM SAF service specifications found at the CM SAF website (www.cmsaf.eu). The quality of the CM SAF input data is documented on a regular basis within the CM SAF validation reports. Limitations of the CM SAF data are described in the CM SAF product user manuals. Similar documentation is available for data sets of other providers, which is referenced in the corresponding RCC-CM product description sheets. 
For some satellite-based products, comparisons with in situ measurements are done (e.g. for clouds, water vapour and sunshine duration) and validation results are provided. A detailed comparison of gridded station-based and satellitebased sunshine duration showed rather good consistencies between the products (for a broader discussion refer to Kothe et al., 2013). For comparison purposes, also reanalyses data are used for some parameters (e.g. global radiation; refer to Krähenmann et al., 2013).

As an outlook, the RCC-CM satellite monitoring aims on updating the climate information records as soon as new climate data records become available. Generally, there is a need for more regularly updated CDRs. Trenberth et al. (2013) point out the increasing demands for short-term assessments of the current climate, especially when major climate events occur. Within an RCC-CM-led study, Krähenmann et al. (2013) proposed a method for the adjustment of CDRs for the integrated use with near-real time data, based on an example using data sets for global radiation. The method consists of homogeneity tests and shift-size adjustments and motivates for the operational generation of nearreal-time climate data records in order to facilitate a better analysis of the current state of the climate and to provide better climate services. Although the method has been developed for SIS data sets it is, in principle, applicable for the adjustment of CDRs addressing other ECVs as well.

Future perspectives of the RCC-CM activities are the provision of other climate indices, the exploitation of daily data for the monitoring of more flexible timescales (e.g. for extreme events) and the ongoing improvement of products.

Acknowledgements. Cloud, albedo, radiation and water vapour data were provided by the EUMETSAT CM-SAF hosted by Deutscher Wetterdienst (www.cmsaf.eu). Long-term records of soil moisture and snow cover were provided by ESA Soil Moisture CCI (www.esa-soilmoisture-cci.org) and ESA GlobSnow (www.globsnow.info), respectively. EUMETSAT H-SAF (hsaf.meteoam.it) is acknowledged for the provision of near-realtime data of soil moisture and snow cover. CDO was used in this work, which is a development by Uwe Schulzweida (2014) at the Max Planck Institute for Meteorology. The R project and many volunteers providing additional packages are also acknowledged. The rasterVis package was used for the generation of Hovmöller plots and the solaR package for the sunshine duration retrieval. These packages were developed by Oscar Perpiñán Lamigueiro, who is gratefully acknowledged for providing support. We thank Andrea Kaiser-Weiss and two anonymous reviewers for constructive suggestions for improving the manuscript.

Edited by: C. Buontempo

Reviewed by: two anonymous referees

\section{References}

Brocca, L., Melone, F., Moramarco, T., Wagner, W., and Hasenauer, S.: ASCAT SoilWetness Index validation through in-situ and modeled soil moisture data in Central Italy, Remote Sens. Environ., 114, 2745-2755, 2010.

Dowell, M., Lecomte, P., Husband, R., Schulz, J., Mohr, T., Tahara, Y., Eckman, R., Lindstrom, E., Wooldridge, C., Hilding, S., Bates, J., Ryan, B., Lafeuille, J., and Bojinski, S.: Strategy Towards an Architecture for Climate Monitoring from Space, available at: http://www.wmo.int/pages/prog/sat/documents/ARCH_ strategy-climate-architecture-space.pdf (last access: 25 January 2014), 2013.

GCOS: Systematic observation requirements for satellite-based products for climate, 2011 update, WMO GCOS Report No. 154, 2011.

Hocke, K. and Kämpfer, N.: Hovmöller diagrams of climate anomalies in NCEP/NCAR reanalysis from 1948 to 2009, Clim. Dynam., 36, 355-364, 2009.

Hollmann, R., Merchant, C., Saunders, R., Downy, C., Buchwitz, M., Cazenave, A., Chuvieco, E., Defourny, P., de Leeuw, G., Forsberg, R., Holzer-Popp, T., Paul, F., Sandven, S., Sathyendranath, S., van Roozendael, M., and Wagner, W.: The ESA Climate Change Initiative: Satellite Data Records for Essential Climate Variables, B. Am. Meteorol. Soc., 94, 1541-1552, 2013.

Karlsson, K.-G., Riihelä, A., Müller, R., Meirink, J. F., Sedlar, J., Stengel, M., Lockhoff, M., Trentmann, J., Kaspar, F., Hollmann, R., and Wolters, E.: CLARA-A1: a cloud, albedo, and radiation dataset from 28 yr of global AVHRR data, Atmos. Chem. Phys., 13, 5351-5367, doi:10.5194/acp-13-5351-2013, 2013.

Kothe, S., Good, E., Obregon, A., Ahrens, B., and Nitsche, H.: Satellite-based sunshine duration for Europe, Remote Sens., 5, 2943-2972, 2013.

Krähenmann, S., Obregon, A., Müller, R., Trentmann, J., and Ahrens, B.: A Satellite-Based Surface Radiation Climatology Derived by Combining Climate Data Records and Near-RealTime Data, Remote Sens., 5, 4693-4718, 2013.

Lattanzio, A., Schulz, J., Matthews, J., Okuyama, A., Theodore, B., Bates, J. J., Knapp, K. R., Kosaka, Y., and Schüller, L.: Land Surface Albedo from Geostationary Satellites: A Multiagency Collaboration within SCOPE-CM, B. Am. Meteorol. Soc., 94, 205-214, 2013.

Liu, Y. Y., Dorigo, W. A., Parinussa, R. M., de Jeu, R. A. M., Wagner, W., McCabe, M. F., Evans, J. P., and van Dijk, A. I. J. M.: Trend-preserving blending of passive and active microwave soil moisture retrievals, Remote Sens. Environ., 123, 280-297, 2012.

Metsämäki, S., Mattila, O.-P., Pulliainen, J., Niemi, K., Luojus, K., and Böttcher, K.: An optical reflectance model-based method for fractional snow cover mapping applicable to continental scale, Remote Sens. Environ., 123, 508-521, 2012.

NRC: Climate Data Records from Environmental Satellites, National Academies Press, Washington D.C., 2004.

Peterson, T. C. and Baddour O.: Towards an enhanced climate system monitoring: challenges and perspectives, Clim. Res., 47, 2128, 2011.

Posselt, R., Müller, R. W., Stöckli, R., and Trentmann, J.: Remote sensing of solar surface radiation for climate monitoring - the CM-SAF retrieval in international comparison, Remote Sens. Environ., 118, 186-198, 2012. 
Sanchez-Lorenzo, A., Wild, M., and Trentmann, J.: Validation and stability assessment of the monthly mean CM SAF surface solar radiation dataset over Europe against a homogenized surface dataset (1983-2005), Remote Sens. Environ., 134, 355-366, 2013.

Schulz, J., Albert, P., Behr, H.-D., Caprion, D., Deneke, H., Dewitte, S., Dürr, B., Fuchs, P., Gratzki, A., Hechler, P., Hollmann, R., Johnston, S., Karlsson, K.-G., Manninen, T., Müller, R., Reuter, M., Riihelä, A., Roebeling, R., Selbach, N., Tetzlaff, A., Thomas, W., Werscheck, M., Wolters, E., and Zelenka, A.: Operational climate monitoring from space: the EUMETSAT Satellite Application Facility on Climate Monitoring (CM-SAF), Atmos. Chem. Phys., 9, 1687-1709, doi:10.5194/acp-9-1687-2009, 2009.

Schulzweida, U.: CDO User's Guide, version 1.6.3, MPI for Meteorology, Germany, available at: https://code.zmaw.de/projects/ cdo/embedded/1.6.3/cdo.pdf (last access: 12 May 2014), 2014.

Trenberth, K. E., Anthes, R. A., Belward, A., Brown, O., Haberman, E., Karl, T. R., Running, S., Ryan, B., Tanner, M., and Wielicki, B.: Challenges of a Sustained Climate Observing System, in: Climate Science for Serving Society: Research, Modelling and Prediction Priorities, edited by: Hurrell, J. W. and Asrar, G., Springer, Berlin, Germany, 2013.
Wagner, W., Dorigo, W., de Jeu, R., Fernandez, D., Benveniste, J., Haas, E., and Ertl, M.: Fusion of active and passive microwave observations to create an Essential Climate Variable data record on soil moisture, ISPRS Annals of the Photogrammetry, Remote Sensing and Spatial Information Sciences, Volume I7, 2012, XXII ISPRS Congress, 25 August-1 September 2012, Melbourne, Australia, 2012.

Wild, M.: Enlightening Global Dimming and Brightening, B. Am. Meteorol. Soc., 93, 27-37, 2012.

World Meteorological Organization (WMO): Guide to Meteorological Instruments and Methods of Observation, 7th Edn., WMO, Geneva, Switzerland, 2008.

World Meteorological Organization (WMO): SCOPE-CM Phase 2 Implementation Plan: Final Version, Version 1.0, 2012, available at: http://www.wmo.int/pages/prog/sat/documents/SCOPE-CM_ Phase-2-Implementation-Plan (last access: 25 January 2014), 2012. 